\title{
Production of functionalized polyhydroxyalkanoates by genetically modified Methylobacterium extorquens strains
}

\author{
Philipp Höfer ${ }^{1,2,4}$, Young J Choi ${ }^{1}$, Michael J Osborne ${ }^{3}$, Carlos B Miguez', Patrick Vermette ${ }^{2}$, Denis Groleau ${ }^{\text {** }}$
}

\begin{abstract}
Background: Methylotrophic (methanol-utilizing) bacteria offer great potential as cell factories in the production of numerous products from biomass-derived methanol. Bio-methanol is essentially a non-food substrate, an advantage over sugar-utilizing cell factories. Low-value products as well as fine chemicals and advanced materials are envisageable from methanol. For example, several methylotrophic bacteria, including Methylobacterium extorquens, can produce large quantities of the biodegradable polyester polyhydroxybutyric acid (PHB), the best known polyhydroxyalkanoate (PHA). With the purpose of producing second-generation PHAs with increased value, we have explored the feasibility of using $M$. extorquens for producing functionalized PHAs containing C-C double bonds, thus, making them amenable to future chemical/biochemical modifications for high value applications.

Results: Our proprietary M. extorquens ATCC 55366 was found unable to yield functionalized PHAs when fed methanol and selected unsaturated carboxylic acids as secondary substrates. However, cloning of either the phaC1 or the phaC2 gene from $P$. fluorescens GK13, using an inducible and regulated expression system based on cumate as inducer (the cumate switch), yielded recombinant M. extorquens strains capable of incorporating modest quantities of $\mathrm{C}-\mathrm{C}$ double bonds into PHA, starting from either $\mathrm{C} 6=$ and/or $\mathrm{C} 8=$. The two recombinant strains gave poor results with $\mathrm{C} 11=$. The strain containing the phaC2 gene was better at using $\mathrm{C} 8=$ and at incorporating $\mathrm{C}-\mathrm{C}$ double bonds into PHA. Solvent fractioning indicated that the produced polymers were PHA blends that consequently originated from independent actions of the native and the recombinant PHA synthases.

Conclusions: This work constitutes an example of metabolic engineering applied to the construction of a methanol-utilizing bacterium capable of producing functionalized PHAs containing C-C double bonds. In this regard, the PhaC2 synthase appeared superior to the PhaC1 synthase at utilizing $\mathrm{C} 8=$ as source of $\mathrm{C}-\mathrm{C}$ double bonds and at incorporating $\mathrm{C}-\mathrm{C}$ double bonds into PHA from either $\mathrm{C} 6=$ or $\mathrm{C} 8=$. The M. ex-phaC2 strain is, therefore, a promising biocatalyst for generating advanced (functionalized) PHAs for future high value applications in various fields.
\end{abstract}

\section{Background}

Polyhydroxyalkanoates with functional groups (functionalized PHAs) have attracted increasing attention in the last ten years or so [1-9]. It has been generally recognized that important needs and markets exist for various types of functionalized PHAs as advanced materials in areas, such as tissue engineering $[2,10,11]$,

\footnotetext{
* Correspondence: denis.groleau@cnrc-nrc.gc.ca

'Microbial and Enzymatic Technology Group, Bioprocess Centre, Biotechnology Research Institute, National Research Council Canada, 6100 Royalmount Avenue, Montréal, Québec, H4P 2R2, Canada

Full list of author information is available at the end of the article
}

biocomposites [12], various medical applications [5,13], and polymers with tunable properties [6], only to name a few.

Although many types of functionalized PHAs have been described in the literature, generally speaking, the quantities produced have been very modest and barely sufficient to obtain a basic characterization of the physico-chemical properties of the new biomaterials [8]. Several reasons explain the situation and these include high toxicity of many of the key substrates, low accumulation of the desired PHAs and lack of commitment to
C Biomed Central 
developing more efficient, and productive fermentation processes.

A commonly applied route for obtaining polyhydroxyalkanoates with desirable functionalities is to produce PHAs with terminal double bonds followed by chemical modification steps. Carbon double bonds are comparatively inert but can be easily transformed into reactive functional groups under mild reaction conditions. Following this approach, polyhydroxyalkanoates with carboxyl, hydroxyl, epoxy and halogenic groups have been produced ([14] and references therein). Pseudomonas species have been most widely used for producing polyhydroxyalkanoates with double bonds in their side chains since they generate functionalized PHAs at comparably high rates of productivity. The incorporation of functional groups in PHAs by pseudomonads occurs by oxidizing functionality-related substrates via the $\beta$-oxidation pathway. The most commonly used substrate to obtain unsaturated polymeric side chains has been 10undecenoic acid $(\mathrm{C} 11=)$, likely owing to its superior availability compared to other alkenoic acids. The $\beta$-oxidation cycle is accompanied by a partial $\mathrm{C} 2$ reduction so that unsaturated monomers resulting from $\mathrm{C} 11=$ exhibit a length of nine and, respectively, seven carbon atoms. The production of purely unsaturated polyhydroxyalkanoates was reported [15]; however, since chemical modification reactions do not require a double bond in every side chain and saturated substrates are cheaper, sodium alkanoate (C8) or nonanoate (C9) were often co-fed [16-18]. Using continuous culture mode, it was possible to produce structurally tailored poly(3-hydroxyalkanoate-co-3-hydroxyalkenoate)s with defined monomeric compositions [19]. Most functionalized PHAs that have been produced to date belong to the family of medium-chain-length (MCL, C $\geq 6$ ) polyhydroxyalkanoates, in which all monomers have six carbon atoms or more. These PHAs are characterized by rubber-like mechanical properties with low melting temperatures $\left(<100^{\circ} \mathrm{C}\right)$. The combination of medium-chainlength with short-chain-length (SCL, $\mathrm{C} \leq 5$ ) monomers to SCL/MCL-PHAs resulted in copolymers with improved thermo-mechanical properties, however, without functionalities [20-23].

In this study, we present data showing that some newly developed recombinant Methylobacterium extorquens strains can deliver functionalized PHAs containing $\mathrm{C}-\mathrm{C}$ double bonds when fed unsaturated fatty acids. These PHAs comprised short-chainlength (SCL, C $\leq 5$ ) and medium-chain-length (MCL, $6 \leq \mathrm{C} \leq 8)$ monomers and belong to a novel class of PHAs that will likely gain much attention due to their potential for high value applications in various fields including tissue engineering. One reason for choosing a methylotrophic microorganism for such purpose was that an important portion of the production process would use methanol, a simple, inexpensive, very abundant, and non-food substrate [24-26]. Another reason was that the project would contribute to establishing $M$. extorquens as a new cell factory, as strongly advocated in a recent review [27].

\section{Materials and methods \\ Microorganisms}

The proprietary, wildtype strain Methylobacterium extorquens ATCC 55366 was used throughout this study [24]. Fresh plates were prepared from vials stored at $-80^{\circ} \mathrm{C}$. Pre-inocula or inocula were prepared from plates stored at $4^{\circ} \mathrm{C}$. The recombinant $M$. extorquens strains were similarly stored except that medium contained tetracycline at $15 \mathrm{mg} / \mathrm{L}$ to maintain selective pressure.

\section{Culture media}

Two media were used, CHOI4 medium [25] or CHOI5 medium, depending on experiments. $\mathrm{CHOI} 5$ medium is identical to CHOI4 medium except that it contained 33 wt\% less ammonium chloride.

\section{Inoculum preparation}

Starting from cultures maintained on $\mathrm{CHOI} 4$ plates at $4{ }^{\circ} \mathrm{C}, 250-300 \mathrm{~mL}$-shake flasks containing $50 \mathrm{~mL}$ of medium were inoculated and incubated at $30^{\circ} \mathrm{C}, 260$ $\mathrm{rpm}$, for approximately $48 \mathrm{~h}$. The medium contained 0.2 vol\% methanol as sole carbon source. Incubation was extended to $72-96 \mathrm{~h}$ in the case of the recombinant $M$. extorquens strains. The medium used to grow the recombinant strains also contained tetracycline at $15 \mathrm{mg} / \mathrm{L}$.

\section{Cell cultivation for PHA production}

Most experiments were conducted using 2 L-shake flasks containing $500 \mathrm{~mL}$ of either $\mathrm{CHOI} 4$ medium or CHOI5 medium. The media contained an initial concentration of 1 vol\% methanol. Media used with the recombinant strains contained tetracycline at $15 \mathrm{mg} / \mathrm{L}$. For induction of the recombinant phaC genes, cumate (4-isopropylbenzoic acid) was added to a final concentration of $20 \mathrm{mg} / \mathrm{L}$. Whenever applicable, addition of the secondary substrate (carboxylic acids) was usually done after 48 or $72 \mathrm{~h}$, or as specifically indicated in the Results and Discussion section. $1 \mathrm{M} \mathrm{KOH}$ was used for manual $\mathrm{pH}$ control.

Fermentation was performed in a 20 L-bioreactor (Chemap, Switzerland) that was inoculated with $10 \mathrm{vol}$ $\%$ of a $72 \mathrm{~h}$ pre-culture grown in shake flasks. Upon oxygen depletion, methanol (usually 1 vol\%) was manually added with a syringe. The co-substrate 7 octenoic acid $(\mathrm{C} 8=)$ was supplied by the same means. Shortly prior to co-substrate addition, expression of the PHA synthase gene phaC2 was induced by adding 
4-isopropylbenzoic acid to reach a final concentration of $20 \mathrm{mg} / \mathrm{L}$. Microbial growth was monitored by spectrophotometry at $600 \mathrm{~nm}$.

\section{Construction of the recombinant plasmids}

To clone the two polyhydroxyalkanoic acid (PHA) synthase genes phaC1 and phaC2 from Pseudomonas fluorescens GK13, the genomic DNA of $P$. fluorescens GK13 was isolated and subjected to PCR using, for phaC1, the primers PhaC1FNhe (5' -CGC TAG CAT GAG CAA CAA GAA CAA TGA AGA CCT GCA GCG C- 3') (the NheI site is underlined), PhaC1RMFE (5' -GCA ATT GTC AAC GTT CGT GGA CAT AGG TCC CTG G- 3') (the $M f e$ I site is underlined) and, for phaC2, the primers PhaC2FNhe (5' -CGC TAG CAT GCG AGA GAA ACA GGT GTC GGG AGC CTT G3') (the NheI site is underlined), PhaC2RMFE (5' - GCA ATT GTC AGC GCA CGT GCA CGT AGG TGC CGG G- 3') (the $M f e$ I site is underlined), thus, yielding 1680-b $\rho$ and 1683-b $\rho$ PCR products, respectively. The PCR products were digested with NheI and Mfel, and cloned into pAll-gfp (Choi et al., unpublished) digested with the same restriction enzymes to generate pAllphaC1 and pAll-phaC2, respectively (Figure 1).

\section{Attempts to develop a phaC-minus $M$. extorquens strain via gene knock-out}

Attempts were made to engineer a $p h a C$-minus mutant of $M$. extorquens via gene knock-out of the native $p h a C$ gene using the TargeTron ${ }^{\text {tm }}$ Gene Knockout system from Sigma-Aldrich (Oakville, ON, Canada). A good number of mutants were obtained and PCR detection of the

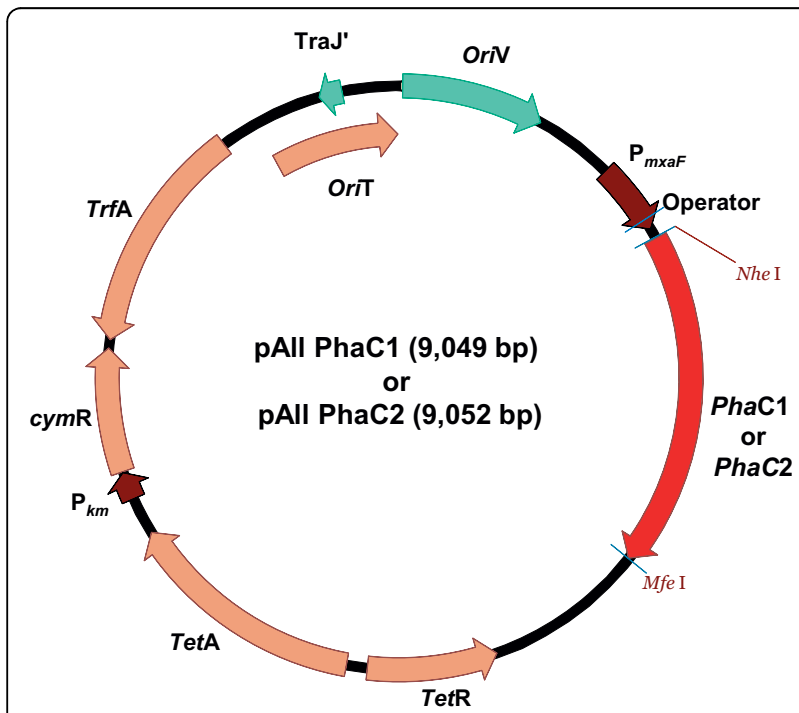

Figure 1 Expression vector. Genetic construction of recombinant plasmids containing the $P$. fluorescens GK13 polyhydroxyalkanoate (PHA) synthase genes phaC1 and phaC2, respectively. integrated intron in 9 randomly selected mutants showed the presence of the insert in all of them and its absence in the wildtype $M$. extorquens strain. However, all the mutants grew very poorly on methanol and, therefore, they could not be employed for further genetic engineering work.

\section{Electroporation of $M$. extorquens}

Competent $M$. extorquens cells were prepared as previously described $[28,29]$. Competent cells were mixed in an Eppendorf tube with $1.0 \mathrm{~g}$ of recombinant plasmid DNA (pAll-phaC1 or pAll-phaC2 ) and the tubes placed on ice for $20 \mathrm{~min}$. The mixtures were transferred to an ice-cold electroporation cuvette and treated in a BioRad electroporator $(25 \mu \mathrm{F}, 200 \Omega, 5 \mathrm{~ms}, 2.5 \mathrm{kV} / \mathrm{cm})$. Immediately thereafter, $1 \mathrm{~mL}$ of CHOI medium [25] was added to the cuvette. The cell suspension was transferred to a $15 \mathrm{~mL}$ tube and incubated at $30^{\circ} \mathrm{C}$ for $5 \mathrm{~h}$, then, $100 \mu \mathrm{L}$ of culture was spread on selective plates (CHOI agar with $35 \mu \mathrm{g}$ of tetracycline per $\mathrm{mL}$ ). The plates were incubated at $30^{\circ} \mathrm{C}$ for $48 \mathrm{~h}$ until colonies appeared. Typically, about 300-500 transformants per plate were obtained.

\section{SDS-polyacrylamide gel electrophoresis}

Crude extracts of recombinant $M$. extorquens cultures were prepared using a French press and protein concentration was estimated by the method of Bradford [30] using the Bio-Rad protein assay kit, with bovine serum albumin as standard. The cell extract samples were diluted in SDS-PAGE Loading Buffer and they were loaded at $10 \mu \mathrm{g}$ per well on a 4-12\% NuPAGE Novex gel (Invitrogen Corp. Carlsbad, CA, USA). Gels were stained with Coomassie Brilliant Blue R-250.

\section{Extraction, purification and solvent fractioning of PHAs}

Culture samples were centrifuged and the resulting pellets were washed in distilled water, methanol and, again, in distilled water followed by re-centrifugation after each washing step. Finally, the biomass was resuspended in water and freeze-dried (LyoStar, Model MNL-055-A, FTS Systems, Stone Ridge, NY). Lyophilized biomass was leached in approximately $20 \times$ volume $(\mathrm{v} / \mathrm{w})$ of chloroform overnight in a rotary shaker at $30^{\circ} \mathrm{C}$. The soaked cells were then filtered through Whatman \#4 paper (Maidstone, UK) and the filtrate purged with nitrogen. Resulting polymer gels were re-dissolved in chloroform and subjected to precipitation overnight in $10 \times$ volume $(\mathrm{v} / \mathrm{v})$ methanol at $4^{\circ} \mathrm{C}$. Finally, precipitates were filtered through one sheet of Fisher Scientific P5 paper (Hampton, $\mathrm{NH}$ ) and air-dried.

Freeze-dried biomass resulting from fermentation was leached in $20 \times$ volume $(\mathrm{v} / \mathrm{w})$ of chloroform or acetone for at least $6 \mathrm{~h}$ in a Branson model 5200 sonicator 
(Danbury, CT) at $60^{\circ} \mathrm{C}$. The soaked cells were then vacuum-filtered through Whatman \#4 paper (Maidstone, UK) and the filtrate boiled down in a Rotavapor (Büchi, Switzerland). Resulting polymer gels were re-dissolved in chloroform and subjected to precipitation overnight in $10 \times$ volume $(\mathrm{v} / \mathrm{v})$ methanol at $4^{\circ} \mathrm{C}$. Finally, precipitates were vacuum-filtered through two sheets of Fisher Scientific P5 paper (Hampton, NH) and air-dried. Chloroformextracted PHAs were fractioned by hot acetone in a Soxhlet apparatus as previously described [31].

\section{Analysis of the PHAs \\ GC-FID}

GC-FID analysis was carried out as follows. Biomass samples were centrifuged in $50 \mathrm{~mL}$ conical Sarstedt tubes (Nümbrecht, Germany) and the pellets lyophilized. Methanolysis was used for analyzing the intracellular PHA content. Briefly, the dry biomass was treated with acidified methanol in the presence of benzoic acid as internal standard at $100^{\circ} \mathrm{C}$ for $3 \mathrm{~h}$ to convert 3-hydroxyalkanoate monomers to the corresponding methyl esters. The methyl esters were extracted in chloroform for subsequent analysis in a gas chromatographic system (Agilent 6890 GC-FID; Agilent Technologies, Wilmington, CA). PHBV from Sigma-Aldrich (Oakville, ON, Canada) and $\mathrm{PHBHx}$ from Procter \& Gamble (Cincinnati, $\mathrm{OH}$ ) were used as PHA standards. Purified biopolyesters were analyzed by the same method.

NMR

Equipment and general conditions used Solution NMR spectra were acquired at $25^{\circ} \mathrm{C}$ on samples dissolved in deuterated chloroform on a Varian Inova 600 $\mathrm{MHz}$ spectrometer equipped with a $\mathrm{HCN}$ coldprobe and $\mathrm{Z}$ gradient. ${ }^{1} \mathrm{H} 1 \mathrm{D}$ spectra were acquired with a sweep width of $12000 \mathrm{~Hz}$ and 128 transients. Assignment of ${ }^{1} \mathrm{H}$ and ${ }^{13} \mathrm{C}$ resonances were achieved via ${ }^{1} \mathrm{H}_{-}{ }^{13} \mathrm{C}$ correlated spectra detecting naturally abundant ${ }^{13} \mathrm{C}$. The ${ }^{1} \mathrm{H}-{ }^{13} \mathrm{C}$ Heteronuclear Single Quantun Coherence (HSQC) [32] and multiplicity edited HSQC spectra were acquired with $2048\left(\mathrm{t}_{2}\right) \times 200\left(\mathrm{t}_{1}\right)$ complex points and ${ }^{1} \mathrm{H}$ and ${ }^{13} \mathrm{C}$ sweep widths of 10000 and $27145 \mathrm{~Hz}$, respectively. Broadband ${ }^{13} \mathrm{C}$ decoupling was achieved during acquisition using WURST2 decoupling over $140 \mathrm{ppm}$. Typically, 128 scans were acquired for each $t_{1}$ value. HMBC (Heteronuclear Multiple Bond Correlation, [33]) and $\mathrm{H} 2 \mathrm{BC}$ (Heteronuclear 2-Bond Correlation, [34]) experiments were acquired with 200 complex (H2BC) and real (HMBC) points in $\mathrm{t} 1$ with ${ }^{1} \mathrm{H}$ and ${ }^{13} \mathrm{C}$ sweep widths of 10000 and $36192 \mathrm{~Hz}$, respectively and 256 transients. All 2D spectra were processed with nmrPipe [35] and analyzed using NMRView [36]. PPM values are quoted relative to TMS. A detailed description for an example of applied NMR analysis is provided as Appendix.

\section{Chemicals}

Pentanoic acid (C5) was obtained from A \& C American Chemicals Ltd. (Saint-Laurent, QC, Canada), 99\% purity; 5-hexenoic acid (C6=) was obtained from either SigmaAldrich or TCI America (Portland, OR), both at $98 \%$ purity; 7-octenoic acid ( $\mathrm{C} 8=$ ) was from Richman Chemical Inc. (Lower Gwynedd, PA), 98\% purity. The following carboxylic acids were all from Sigma-Aldrich: 10-undecenoic acid (C11=), 98\% purity; 4-pentenoic acid (C5=), 97\% purity; trans-2-pentenoic acid ( $t-C 5=)$, 98\% purity; hexanoic acid (C6), 99\% purity.

\section{Results and Discussion}

\section{Production of unsaturated PHAs using the wild-type} strain

The potential of the pink facultative methylotroph M. extorquens ATCC 55366 was tested to utilize various fatty acids including fatty acids with $\mathrm{C}-\mathrm{C}$ double bonds. The assays were performed in shake flasks using medium CHOI4 or medium CHOI5. Nearly 100 shake flask assays were conducted. The $M$. extorquens cultures were grown first on methanol as sole carbon and energy source and the fatty acid of interest was added at some point to the growing cultures, generally at a final concentration in the $0.1-0.3 \%$ range. A summary of the substrates tested and of the results obtained is presented in Table 1. Only the homopolymer PHB or the copolymer PHBV was detected in the cultures as no other peaks apart from 3-hydroxybutyrate (3HB) and 3-hydroxypentanoate $(3 \mathrm{HP}=3 \mathrm{HV})$ were seen in $\mathrm{GC}$ chromatograms. As can be seen, feeding of C5-fatty acids led to accumulation of the copolymer PHBV solely and, unfortunately, no trace of $\mathrm{C}-\mathrm{C}$ double bounds could be detected in the PHAs produced upon feeding C5-fatty acids containing a $\mathrm{C}$ - $\mathrm{C}$ double bond. Control of $\mathrm{pH}$ is a key factor when cultures are fed free carboxylic acids. In the present study, efforts were made to minimize $\mathrm{pH}$ effects by regular, manual addition of $1 \mathrm{M} \mathrm{KOH}$ in order to maintain $\mathrm{pH}$ within a reasonable range favorable for growth and substrate utilization. Given the extent of our screening efforts, it may be reasonably concluded that the wildtype M. extorquens ATCC 55366 strain was unable to accumulate functionalized PHAs containing C-C double bonds. As a consequence, the next step consisted in developing $M$. extorquens strains harboring heterologous PHA synthase genes allowing for biosynthesis of the wanted functionalized PHAs.

\section{Metabolic engineering of $M$. extorquens for modifying its PHA-synthesizing machinery}

The inability of the wildtype $M$. extorquens strain to yield the desired PHAs was assumed to be due to a too narrow substrate specificity of the wildtype PHA synthase enzyme. As done by several research groups 
Table 1 Utilization of various fatty acids, unsaturated or saturated, for growth and PHA accumulation by M. extorquens ATCC 55366

\begin{tabular}{lrr}
\hline Co-substrate & $\begin{array}{r}\text { Monomeric composition of the produced } \\
\text { C4:0 } \\
\text { [mol\%] }\end{array}$ & $\begin{array}{r}\text { C5:0 } \\
\text { [mol\%] }\end{array}$ \\
\hline $\mathrm{C} 5$ & 30.4 & 69.6 \\
$\mathrm{C} 5=^{2}$ & 100 & - \\
$\mathrm{C} 5=$ & $>99$ & $\mathrm{tr}^{3}$ \\
$\mathrm{t}-\mathrm{C} 5=$ & $>99$ & $\mathrm{tr}^{3}$ \\
$\mathrm{t}-\mathrm{C} 5=$ & 87.9 & 12.1 \\
$\mathrm{C} 6$ & $>99$ & $\mathrm{tr}$ \\
$\mathrm{C} 6$ & $>99$ & $\mathrm{tr}$ \\
$\mathrm{C} 6$ & 100 & $\mathrm{tr}$ \\
$\mathrm{C} 6=^{4}$ & 100 & - \\
$\mathrm{C} 8=$ & 98.7 & 1.2 \\
$\mathrm{C} 8=^{5}$ & 100 & - \\
$\mathrm{C} 11={ }^{6}$ & $>99$ & $\mathrm{tr}$ \\
$\mathrm{C} 11={ }^{7}$ & 100 & - \\
\hline
\end{tabular}

${ }^{1} \mathrm{CX}: \mathrm{Y}=$ double bond at position $\mathrm{Y}$ of monomeric chain length $\mathrm{X}$;

${ }^{2}$ Three (3) similar samples were analyzed;

${ }^{3} \operatorname{tr}=$ detected in trace quantity;

${ }^{4}$ Six (6) similar samples were analyzed;

${ }^{5}$ Three (3) similar samples were analyzed;

${ }^{6}$ Eight (8) similar samples were analyzed;

${ }^{7}$ Three (3) similar samples were analyzed.

[37-44], we then decided to engineer $M$. extorquens strains harboring different PHA synthase ( $p h a C)$ genes known or assumed to code for PHA synthases of broader substrate specificity. After careful review of the literature, the phaC1 and phaC2 genes present in the $P$. fluorescens GK13 strain were selected because the PHA synthesis machinery of this bacterium is able to also produce longer PHA chains $[23,45]$, an indication of broader substrate specificity. In a first step, the phaC1 and phaC2 genes were successfully isolated using PCR and the isolated genes were identical to the reported sequences [45]. In a second step, the two phaC genes were cloned into the pAll plasmid (Figure 1) and inducible expression was driven by the cloned methanol dehydrogenase (PmxaF) of $M$. extorquens under control of regulatory elements of $P$. putida F1. This new technology for inducible and regulated gene expression was developed by our group for $M$. extorquens $[28,29]$. It may be described as follows: (A) In the absence of the chemical inducer $(\mathrm{p}$-isopropylbenzoate $=$ cumate $)$, the repressor protein cymR is bound to the operator site upstream of the gene of interest and transcription is blocked; (B) addition of cumate as inducer leads to formation of the cymR-cumate complex, followed by detachment of cymR from the operator and activation of the transcription of the downstream gene.

The two recombinant $M$. extorquens strains, $M$. exphaC1 and M. ex-phaC2, as well as the M. extorquens wildtype strain were grown in $\mathrm{CHOI}$ medium containing methanol, plus tetracycline in the case of the two recombinant strains. As shown in Figure 2, addition of cumate, the inducer, led to expression of both the phaC1 gene (lane 4) and of the phaC2 gene (lane 6). Both protein bands indicated a molecular mass of approximately $62 \mathrm{kDa}$. Interestingly, a strong band, with an apparent molecular mass of $40 \mathrm{kDA}$, was present in the samples for noninduced $M$. ex-phaC1 cells (lane 3) or $M$. ex-phaC2 cells (lane 5). The same band was quasi inexistent in induced cells of the same recombinant strains. This additional band is certainly not related to the insert (phaC gene) since it has been observed with other recombinant $M$. extorquens strains harboring different and various inserts. Ideally, the two recombinant phaC genes should have been introduced into a phaC -minus mutant of $M$. extorquens. Unfortunately, although we were able to obtain such mutants, the mutants grew very poorly in the culture media containing methanol as sole carbon source. A similar observation on the growth of strain AMI of M. extorquens on $\mathrm{C} 1$ and $\mathrm{C} 2$ compounds was also reported by Korotkova

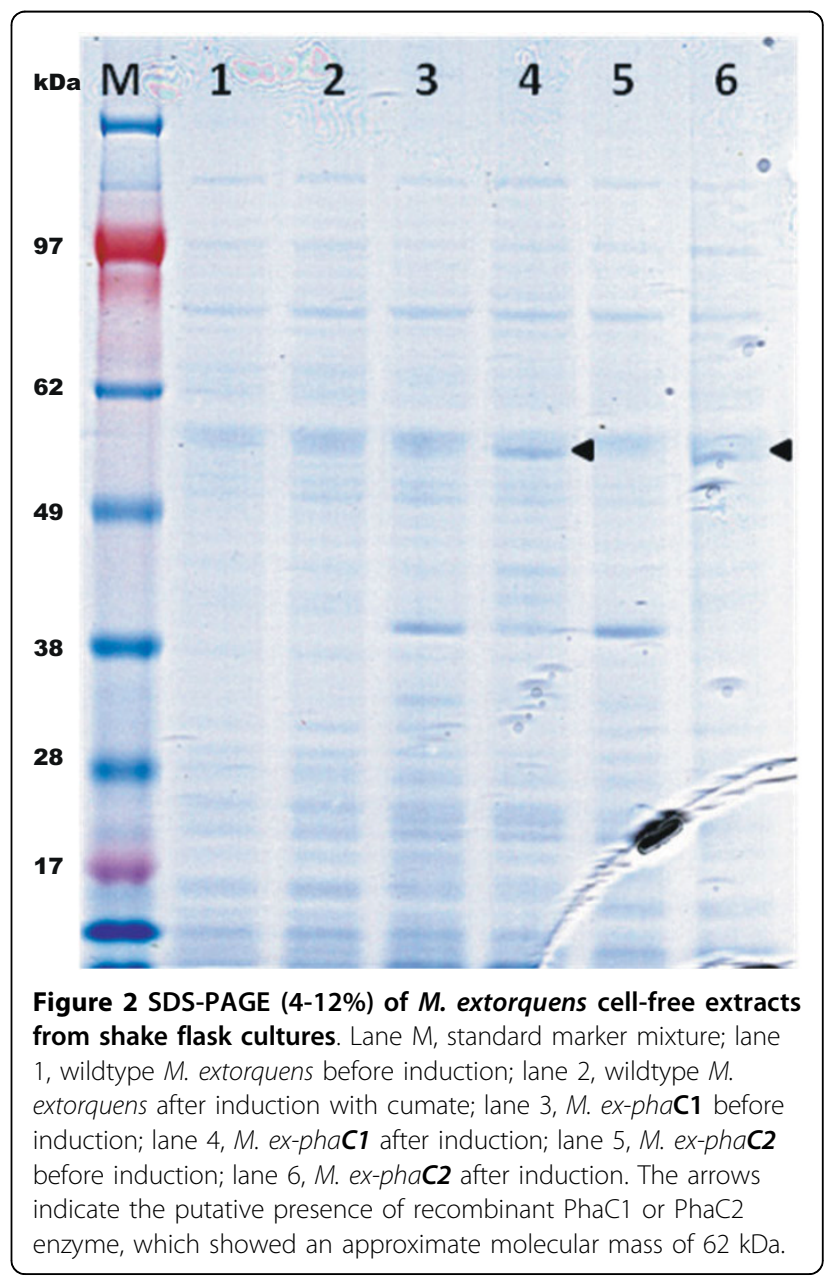


and Lidstrom [46]. Consequently, because of the presence of the native PHA synthase, PHA blends comprised of PHB and functionalized PHAs could be expected.

\section{Growth of the two recombinant $M$. extorquens strains}

As illustrated in Figure 3, the two recombinant strains grew well on methanol but maximal growth of the two strains was inferior to that of the wildtype strain. At 70$72 \mathrm{~h}$, addition of a mixture of methanol +10 -undecenoic acid $(\mathrm{C} 11=)$ resulted in further growth for the three strains but growth, as measured by optical density, rapidly reached a plateau in all three cases. The $M$. exphaC2 strain appeared to grow better than the $M$. exphaC1 strain under the conditions used. Phase contrast microscopy of the cultures showed the presence of granules, tentatively identified as PHB (or PHA) granules, in cells from the three $M$. extorquens strains and the granules increased in size over time. The appearance of the granules occurred between $68 \mathrm{~h}$ and $74 \mathrm{~h}$ and it coincided with the addition of the methanol $+\mathrm{C} 11=$ mixture (Figure 3, arrow).

Many shake flask studies were conducted using various feeding strategies to verify the growth behavior in the presence of alkenoic acids. Cultures were started using methanol as main substrate and, at desired times, the selected unsaturated carboxylic acid was added to favor accumulation of a functionalized PHA. To minimize $\mathrm{pH}$ effects, attempts were made to maintain $\mathrm{pH}$ by

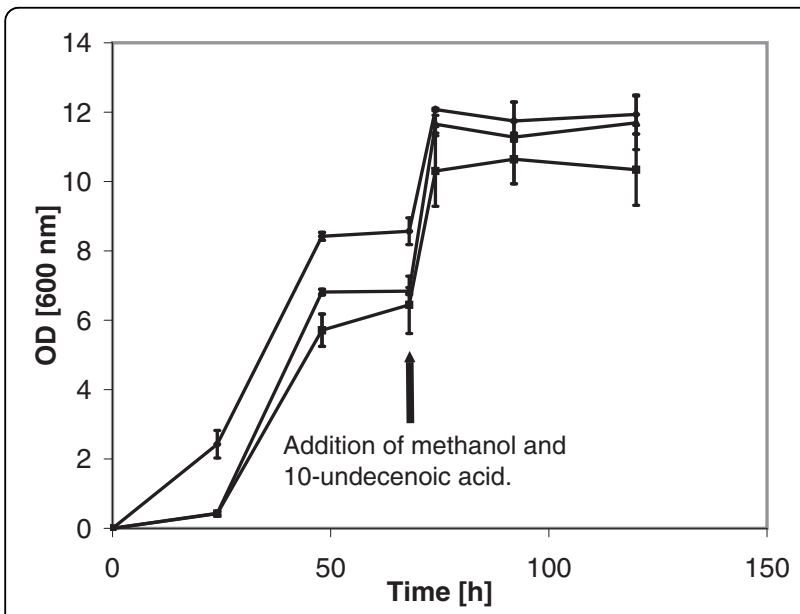

Figure 3 Growth of $\boldsymbol{M}$. extorquens strains. Growth of the wildtype $M$. extorquens strain and of the two recombinant $M$. extorquens strains on methanol (Phase 1, 0-68 h) and on methanol +10 -undecenoic acid (C11=) (Phase 2, 68 h-end). Addition of the mixture is indicated by the arrow. $(\bullet)$ wildtype strain, $\mathrm{n}=3$; $(\bullet)$ M. ex-phaC1 strain, $n=3$; $(\mathbf{\Delta})$ M. ex-phaC2 strain, $n=2$. The medium initially contained 1 vol\% methanol. At $68 \mathrm{~h}$, methanol and $\mathrm{C} 11=$ were added to give a final concentration of 2 vol\% and 0.2 vol\% of methanol and $\mathrm{C} 11=$, respectively. manual addition of $1 \mathrm{M} \mathrm{KOH}$. The growth results for strain $M$. ex-phaC1 are shown in Figure 4 while those for strain $M$. exphaC2 are shown in Figure 5. Pulse addition of the carboxylic acid is indicated by arrows. The two $M$. extorquens strains (Figure $4 \mathrm{~A}$ and Figure $5 \mathrm{~A})$ continued to grow, although more slowly, upon addition of 5-hexenoic acid ( $66=)$ and "respectable" biomass levels (OD600nm) were obtained, between 8 and 11 , with all flasks except for one case. The $\mathrm{pH}$ profile varied with each flask but $\mathrm{pH}$ values were always between 6.2 and 7.7. The growth results on 7-octenoic acid $(\mathrm{C} 8=)$ are illustrated in Figure 4B (M. ex-phaC1)
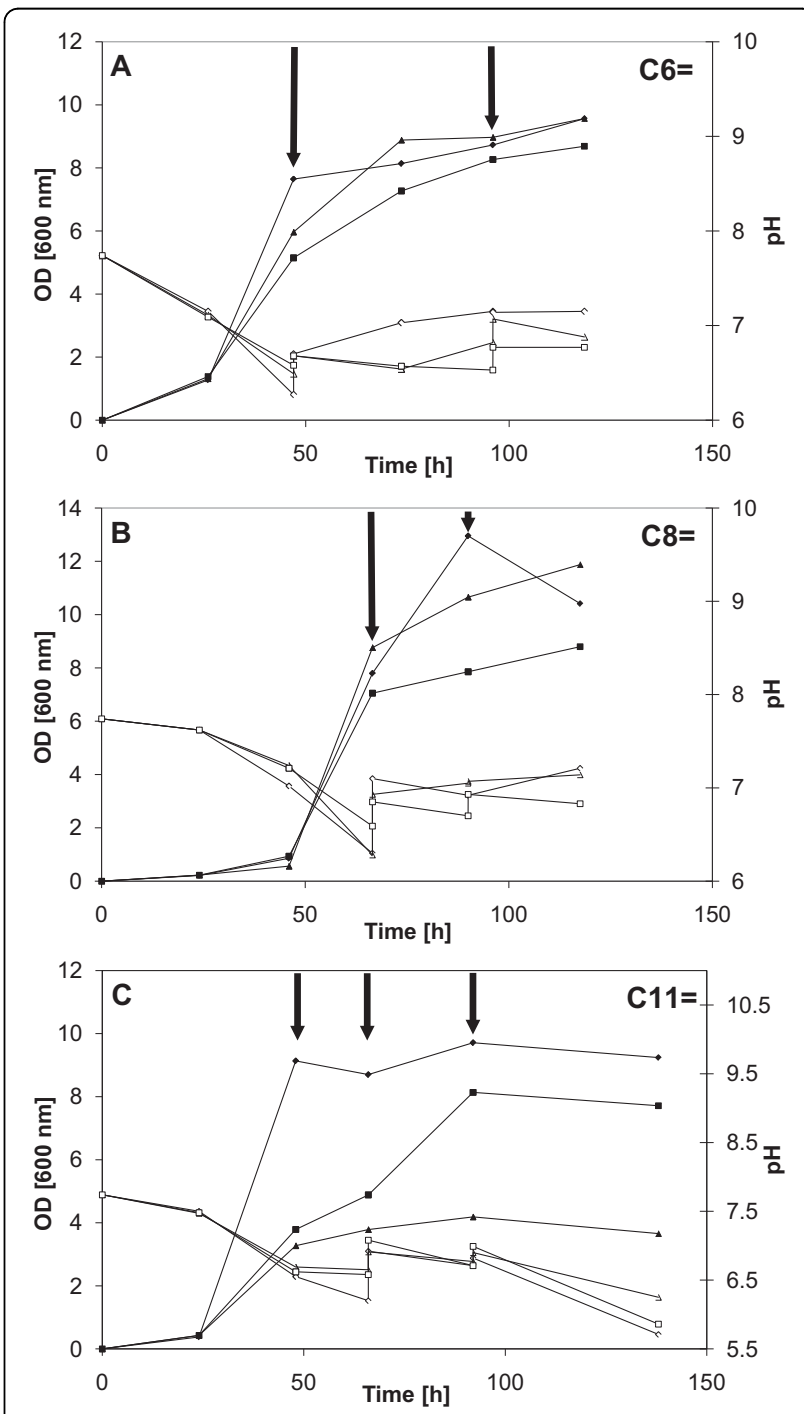

Figure 4 Growth of the $M$. ex-phaC1 strain on selected unsaturated carboxylic acids. Cultures were grown first on methanol, then, the selected unsaturated carboxylic acid was added pulse-wise (indicated by arrows). Partial control of $\mathrm{pH}$ was done using $1 \mathrm{M} \mathrm{KOH}$ to prevent intolerable extremes in $\mathrm{pH}$. Closed symbols: OD at $600 \mathrm{~nm}$, open symbols: pH. (A) 5-hexenoic acid (C6=); (B) 7-octenoic acid (C8=); (C) 10-undecenoic acid (C11=). 

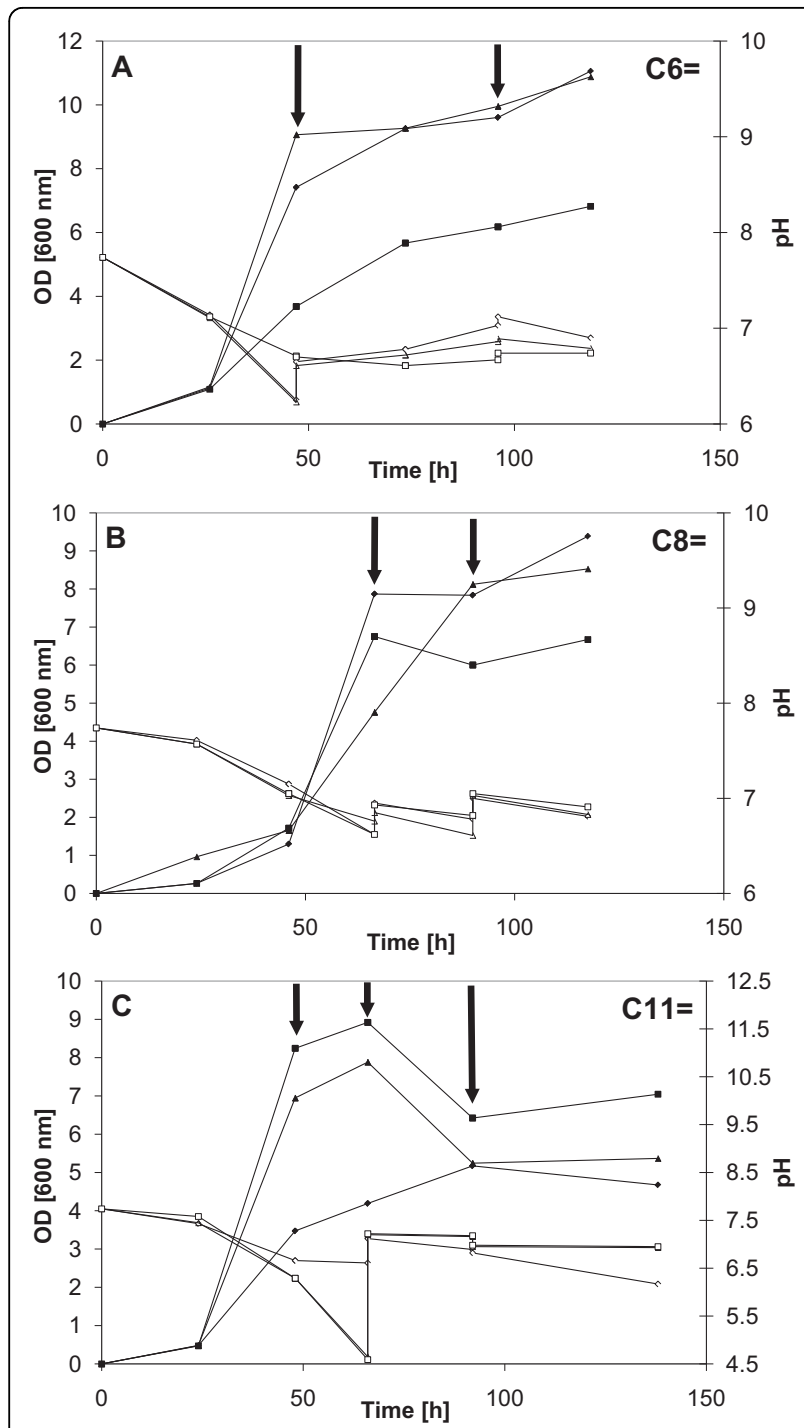

Figure 5 Growth of the $M$. ex-phaC2 strain on selected unsaturated carboxylic acids. Cultures were grown first on methanol, then, the selected unsaturated carboxylic acid was added pulse-wise (indicated by arrows). Partial control of $\mathrm{pH}$ was done using $1 \mathrm{M} \mathrm{KOH}$ to prevent intolerable extremes in $\mathrm{pH}$. Closed symbols: $\mathrm{OD}$ at $600 \mathrm{~nm}$, open symbols: $\mathrm{pH}$. (A) 5-hexenoic acid (C6=); (B) 7-octenoic acid (C8=); (C) 10-undecenoic acid (C11=).

and in Figure 5B (M. ex-phaC2). The results were similar to those obtained with 5-hexenoic acid $(\mathrm{C} 6=)$ except that the OD600nm profiles varied significantly more between flasks. As with 5-hexenoic acid, the $\mathrm{pH}$ profile varied with each flask but $\mathrm{pH}$ values were always between 6.2 and 7.6. With 10-undecenoic acid (C11=), however, growth appeared even more "erratic" as there was significant variation in the OD600nm profile between flasks (Figure $4 \mathrm{C}$ and Figure $5 \mathrm{C}$ for strains $M$. exphaC1 and $M$. ex-phaC2, respectively). Maximal OD600nm values varied between only 4 and almost 10
(Figure 4C). Overall, most of the biomass was obtained from methanol, i.e., before addition of the respective carboxylic acid, due to the well-known toxicity of such acids. Probably due to the lack of acceptable $\mathrm{pH}$ control, significant differences in optical density profiles were observed between shake flasks, especially when C11= was fed (Figures $4 \mathrm{C}$ and $5 \mathrm{C}$ ). Interestingly, in several cases, growth continued after addition of the "toxic" carboxylic acid. Several examples are depicted in Figures 4 and 5 . The optical density values obtained are very comparable to values found in the recent literature for similar work $[15,17,37-39,47]$. In this study, as in many others, emphasis was on strain development, not on process optimization. With $\mathrm{C} 11=$ as co-substrate, manual maintenance of the $\mathrm{pH}$ was also more problematic, $\mathrm{pH}$ values lower than 6 were recorded with both strains, reaching even near 4.5 at one point with strain $M$. exphaC2.

\section{Determination of the monomeric composition of polyhydroxyalkanoates}

Selected PHA samples were chosen as representatives and submitted to $1 \mathrm{D}$ and $2 \mathrm{D}$ NMR analysis for obtaining proof that $\mathrm{C}-\mathrm{C}$ double bonds were present and that at least some of the $\mathrm{C}-\mathrm{C}$ double bonds were located in the PHA side chains. Analysis of the NMR results confirmed both the presence of unsaturated PHA components in the samples and the presence of $\mathrm{C}-\mathrm{C}$ double bonds in the side chains.

Consequently, the representative PHA samples, including a PHA sample produced by the wildtype $M$. extorquens strain, were submitted to $1 \mathrm{D}$ and 2D NMR analyses (see Materials and Methods) to further identify which unsaturated components might be present. The results are summarized in Table 2. The two samples derived from $\mathrm{C} 11$ = yielded poor quality spectra. As representative example, the results for a PHA that was produced by $M$. ex-phaC2 on methanol and 7-octenoic acid will be presented in more detail:

1. The ${ }^{1} \mathrm{H} 1 \mathrm{D}$ spectrum indicated that $3 \mathrm{HB}$ was the major component comprising over $96 \%$ of the total signal (spectrum not shown). Using natural abundance 2D ${ }^{1} \mathrm{H}_{-}{ }^{13} \mathrm{C}$ correlation spectra (Figure 6), it was possible to identify at least 5 minor components present which were assigned to $3 \mathrm{HP}, 3 \mathrm{HHx}, 3 \mathrm{HO}$, $3 \mathrm{HHx}=$ and $3 \mathrm{HO}=$. Chemical shift assignments for these components are shown in Table 3. Finally, at very low contour levels, we were able to detect and assign resonances at the terminus of polymer (these are too weak to detect in Figure 6 but assignments are listed in Table 3);

2. A notable feature of the 2D HSQC spectrum was the presence of high frequency ${ }^{1} \mathrm{H}$ (5.0 ppm and 5.7 
Table 2 1D and 2D NMR analysis of selected PHA samples ${ }^{1}$

\begin{tabular}{cll}
\hline Co-substrate & 1D Analysis & 2D Analysis \\
\hline $\mathrm{C} 6=^{2}$ & $3 \mathrm{HB}$ as major peak $(>90 \%), 3 \mathrm{HHx}={ }^{3}$ & Not performed. \\
$\mathrm{C} 8={ }^{4}$ & $3 \mathrm{HB}$ as major peak $(>96 \%)$ & At least 5 minor components: $3 \mathrm{HP}, 3 \mathrm{HHx}, 3 \mathrm{HHx}=3 \mathrm{HO}$ and $3 \mathrm{HO}=$. \\
$\mathrm{C} 11={ }^{5}$ & Poor quality spectra. \\
- & $3 \mathrm{HB}, 3 \mathrm{HP}$ (very minor) & No detectable unsaturated bonds \\
\hline
\end{tabular}

${ }^{1}$ These samples were chosen as representatives due to availability of enough material and equipment;

${ }^{2}$ Three (3) similar samples were analyzed;

${ }^{3}$ Since $\mathrm{C} 6=$ was the co-substrate, it was concluded that the detected double bonds belonged to $3 \mathrm{HH}=$;

${ }^{4}$ Three (3) similar samples were analyzed;

${ }^{5}$ Two (2) similar samples were analyzed.

ppm) and ${ }^{13} \mathrm{C}$ (115 ppm and $135 \mathrm{ppm}$ ) resonances indicative of double bonds. These were assigned to the $3 \mathrm{HHx}=$ and $3 \mathrm{HO}=$ monomers. Further analysis of the NMR observations indicated that the double bond for these two monomers must be at the end of the alkyl chain;
3. Using the $\mathrm{C} 3$ resonances in the HSQC, we obtained a ratio of $3 \mathrm{HB}: 3 \mathrm{HO}=(1: 0.06), 3 \mathrm{HB}: 3 \mathrm{HHx}=$ (1:0.05), 3HB:3HP (1:0.02), 3HB:3HHx (1:0.008, comparing methyls), 3HB:3HO (1:0.008, comparing methyls).

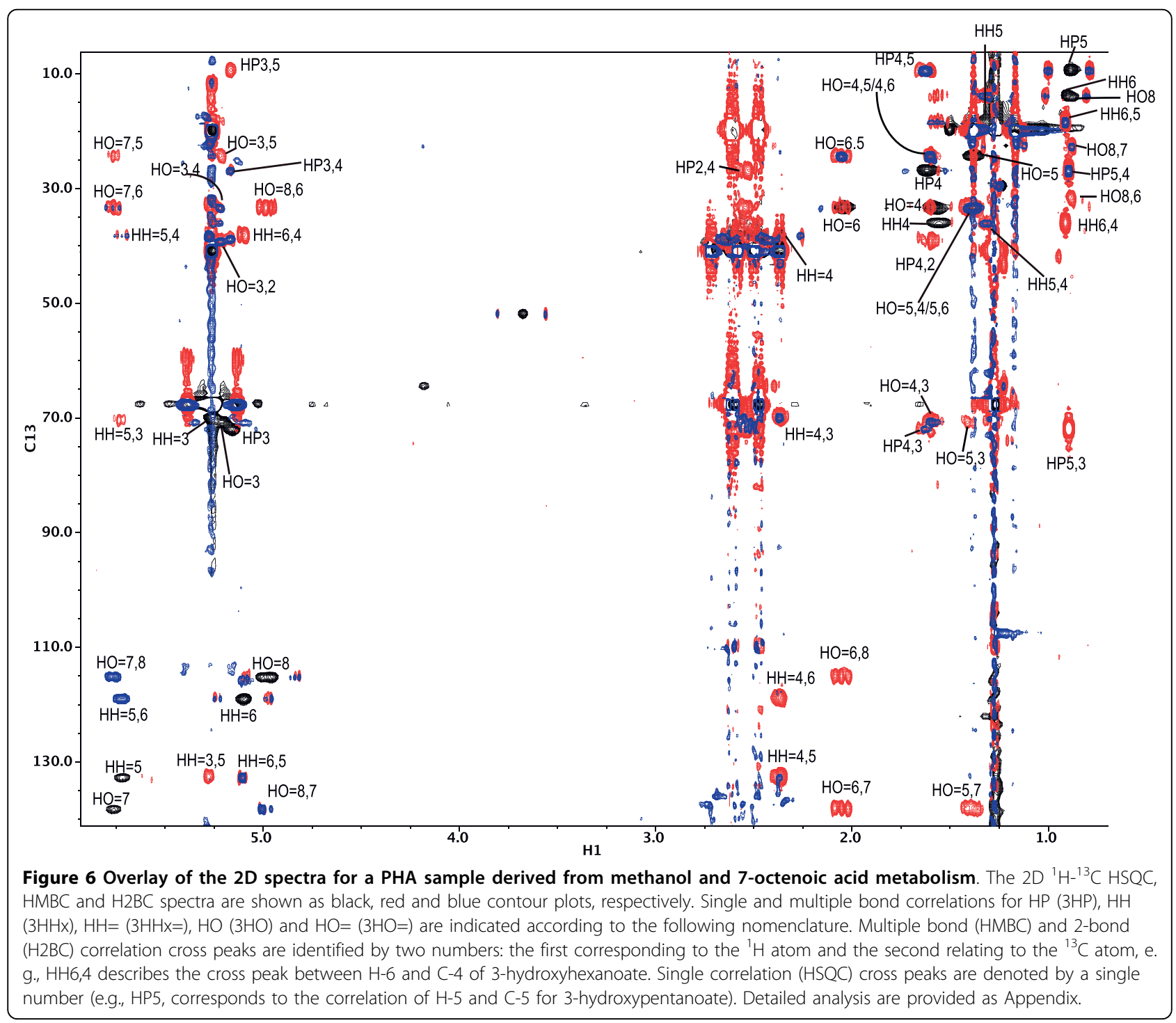


Table 3 Summary of the ${ }^{13}$ C-NMR shift values for a PHA sample derived from methanol and 7-octenoic acid metabolism

\begin{tabular}{ccccccc}
\hline Carbon & $\mathbf{3 H B}$ & $\mathbf{3 H P}$ & $\mathbf{3 H H x}$ & $\mathbf{3 H H x}=$ & $\mathbf{3 H O}=$ & C-terminus \\
\hline 1 & 169.2 & 169.3 & $169.2^{1}$ & $169.2^{1}$ & $169.2^{1}$ & - \\
2 & 40.7 & 38.9 & 39.3 & $39.5-40.8^{1}$ & $39.5-40.8^{1}$ & $43.2\left(\mathrm{CH}_{2}\right)$ \\
3 & 67.7 & 71.9 & 70.7 & 70.06 & 70.8 & $64.5(\mathrm{CH})$ \\
4 & 19.7 & 26.9 & 35.9 & 38.2 & 33.3 & $22.5\left(\mathrm{CH}_{3}\right)$ \\
5 & - & 9.4 & 18.4 & 132.7 & 24.2 & - \\
6 & - & - & 13.8 & 118.9 & 33.2 & - \\
7 & - & - & - & - & 138.3 & - \\
8 & - & - & - & - & 115.2 & - \\
\hline
\end{tabular}

${ }^{1}$ Actual value is uncertain due to overlap from major component (3HB).

Unfortunately, 2D NMR could not be performed with every sample due to cost and equipment availability. However for GC-FID analysis, it was now obvious that 3-hydroxyalkanoate monomers derived from 5-hexenoic acid would result in peaks for $3 \mathrm{HHx}=$ and $3 \mathrm{HHx}$, while peaks for $3 \mathrm{HP}, 3 \mathrm{HHx}=, 3 \mathrm{HHx}, 3 \mathrm{HO}=$ and $3 \mathrm{HO}$ could be expected from metabolism with 7-octenoic acid. Consequently, GC-FID was routinely used thereafter to determine the composition of the PHAs produced and to look for the presence of $\mathrm{C}-\mathrm{C}$ double bonds. Peaks for $3 \mathrm{HB}, 3 \mathrm{HP}$ and $3 \mathrm{HHx}$ were identified from corresponding methanolized PHA standards (see Materials and Methods). Since methyl esters resulting from 3-hydroxyalkenoates have a lower molecular weight compared to their saturated analogs, the peak that was recorded shortly prior to $3 \mathrm{HHx}$ was identified as $3 \mathrm{HHx}=$. In addition to thereby related peaks for $3 \mathrm{HB}, 3 \mathrm{HP}, 3 \mathrm{HHx}=$ and $3 \mathrm{HHx}, \mathrm{GC}$ chromatograms of PHA samples derived from methanol and 7-octenoic acid metabolism showed two more peaks that eluted at later time. From 2D NMR analysis it was concluded that these remaining peaks had to correspond to $3 \mathrm{HO}=$ and, eluted immediately thereafter, to $3 \mathrm{HO}$. Peak areas were used to calculate the proportional monomeric compositions.

\section{Potential of the two recombinant strains for producing functionalized PHAs}

From the start, our intention was to develop M. extorquens strains capable of accumulating functionalized PHAs harboring $\mathrm{C}-\mathrm{C}$ double bonds within the side chains. As done by others, the production of such PHAs requires feeding an unsaturated carboxylic acid in the hope that a portion of the acid will be incorporated into the PHA molecule by the recombinant $\mathrm{PhaC} 1$ or $\mathrm{PhaC} 2$ enzyme, thus, leading to the potential presence of $\mathrm{C}-\mathrm{C}$ double bonds in the PHA side chains.

Numerous shake flask studies were conducted using various unsaturated carboxylic acids, various feeding regimes and process conditions in the hope of identifying initial conditions that could lead to maximization of functionalized PHA production. Resulting PHA samples were generated and analyzed according to NMR and/or GC-FID analysis. As Table 4 indicates, the $M$. ex-phaC1 strain was able to produce PHA containing a small percentage, $0.75 \%$ +/- 0.57\%, of C6:5 bond-containing material starting from $\mathrm{C} 6=$. The same strain, however, was very poor at incorporating $\mathrm{C}-\mathrm{C}$ double bonds when either $\mathrm{C} 8=$ or $\mathrm{C} 11=$ was fed; only trace amounts of $\mathrm{C}-\mathrm{C}$ double bonds were detected. Interestingly, the $M$. ex-phaC1 strain was able to incorporate significant quantities of a $\mathrm{C} 5$ unit starting from $\mathrm{C} 8=$. In this regard, $\mathrm{C} 8=$ appeared much superior as chemical donor. Due to the high toxicity of the carboxylic acids used, cell densities were always low, generally between 1 and $2 \mathrm{~g} / \mathrm{L}$, on a dry weight basis.

As illustrated in Table 4, the M. ex-phaC2 strain appeared better than the $M$. ex-phaC1 strain at incorporating $\mathrm{C} 6: 5$ bonds into PHA (C-C double bond at position 5 of $\mathrm{C} 6$ monomer chain length). An average of

Table 4 Chemical composition of the PHAs extracted from recombinant $M$. extorquens cells grown on methanol + various unsaturated carboxylic acids ${ }^{1}$

\begin{tabular}{|c|c|c|c|c|c|c|c|c|c|}
\hline \multirow{3}{*}{$\begin{array}{l}\text { Strain } \\
\text { phac1 }\end{array}$} & & & \multicolumn{6}{|c|}{ Monomeric composition of the produced $\mathrm{PHA}^{2}$} & \multirow{3}{*}{$\begin{array}{c}\begin{array}{c}\mathrm{C8:0} \\
\text { [mol\%] }\end{array} \\
-\end{array}$} \\
\hline & \multicolumn{2}{|c|}{$\begin{array}{l}\text { Substrate } \\
\text { [mol/L] }\end{array}$} & \multirow{2}{*}{$\begin{array}{c}\begin{array}{c}\text { DCW } \\
\text { [g/L] }\end{array} \\
1.59+/-0.23\end{array}$} & \multirow{2}{*}{$\begin{array}{c}\begin{array}{c}\text { C4:0 } \\
\text { [mol\%] }\end{array} \\
98.11+/-0.89\end{array}$} & \multirow{2}{*}{$\begin{array}{c}\begin{array}{c}\mathrm{C} 5: 0 \\
{[\mathrm{~mol} \%]}\end{array} \\
-\end{array}$} & \multirow{2}{*}{$\begin{array}{c}\begin{array}{c}\text { C6:5 } \\
\text { [mol\%] }\end{array} \\
0.75+/-0.57\end{array}$} & \multirow{2}{*}{$\begin{array}{c}\begin{array}{c}\text { C6:0 } \\
{[\mathrm{mol} \%]}\end{array} \\
1.14+/-0.34\end{array}$} & \multirow{2}{*}{$\begin{array}{c}\begin{array}{c}\mathrm{C8}: 7 \\
{[\mathrm{~mol} \%]}\end{array} \\
-\end{array}$} & \\
\hline & $C 6={ }^{3}$ & 16.82 & & & & & & & \\
\hline & $\mathrm{C} 8={ }^{4}$ & 6.61 & $1.65+/-0.31$ & $97.35+/-1.69$ & $2.65+/-1.68$ & $\operatorname{tr}^{5}$ & $\mathrm{tr}$ & $\operatorname{tr}$ & $\operatorname{tr}$ \\
\hline & $\mathrm{C} 11={ }^{6}$ & 3.43 & $1.11+/-0.28$ & 100 & - & - & - & - & - \\
\hline \multirow[t]{3}{*}{ phac2 } & $C 6={ }^{3}$ & 16.82 & $1.64+/-0.46$ & $91.24+/-5.23$ & - & $4.76+/-2.94$ & $4.00+/-2.30$ & - & - \\
\hline & $C 8={ }^{4}$ & 6.61 & $1.65+/-0.31$ & $84.69+/-4.87$ & $5.28+/-1.13$ & $2.66+/-0.98$ & $2.36+/-0.98$ & $5.01+/-1.82$ & $\operatorname{tr}$ \\
\hline & $\mathrm{C} 11={ }^{6}$ & 3.43 & $0.91+/-0.07$ & 100 & - & - & - & - & - \\
\hline
\end{tabular}

${ }^{1}$ The PHA samples presented here were obtained from experiments shown in Figures 4 and 5 ;

${ }^{2} \mathrm{CX}: \mathrm{Y}=$ double bond at position $\mathrm{Y}$ of monomeric chain length $\mathrm{X}$;

${ }^{3}$ Average $+/$ - standard deviation, $\mathrm{n}=3$;

${ }^{4}$ Average +/- standard deviation, $\mathrm{n}=3$;

${ }^{5}$ tr = detected in trace quantity;

${ }^{6}$ Average +/- standard deviation, $\mathrm{n}=2$. 
$4.76 \%+/-2.94 \%$ of the PHA was made up of C6:5 bondcontaining units upon feeding of $\mathrm{C} 6=$. The same strain appeared also better at incorporating a $\mathrm{C} 6$ monomer from either $\mathrm{C} 6=$ or $\mathrm{C} 8=$. When $\mathrm{C} 8=$ was fed, four of the five samples showed the obvious presence of C8:7 bondcontaining units. The concentrations of C6:5 material and those of a $\mathrm{C} 6$ monomer were also significantly higher. A C5 monomer was detected in the samples derived from $\mathrm{C} 6=$ but it was much more prevalent when $\mathrm{C} 8$ = was fed, an observation valid for both recombinant strains. Feeding of $\mathrm{C} 11=$, as with the first strain, did not lead to production of PHA containing significant percentages of $\mathrm{C}-\mathrm{C}$ double bonds. Cell densities, again, were quite low. Table 4 indicates that PHA containing small quantities of C6:5 material could be obtained with both strains after feeding $\mathrm{C} 6=$ but only the $M$. exphaC2 strain could generate both C6:5 material and C8:7 material when fed $\mathrm{C} 8=$.

The results listed in Table 4 show that PHA material containing modest concentrations of unsaturated C-C bonds could be obtained with the two strains. Three strong conclusions may be drawn from the results. (1) Strain M. ex-phaC2 was better at producing PHA material containing $\mathrm{C}-\mathrm{C}$ double bonds; (2) the same strain was better at producing PHA material containing $\mathrm{C}-\mathrm{C}$ bonds from $\mathrm{C} 8=$; (3) both strains gave very poor results with $\mathrm{C} 11=$. Several groups have observed or hypothesized that $\mathrm{PhaC} 2$ synthases have a lower substrate specificity than $\mathrm{PhaC} 1$ synthases $[37,38,40]$. Other groups have suggested that $\mathrm{PhaC} 1$ and $\mathrm{PhaC} 2$ synthases have different functions $[43,44,48]$. Contrary to observations made with other bacteria, our $M$. extorquens strains gave poor results with $\mathrm{C} 11=$ and, therefore, only $\mathrm{C} 6=$ or $\mathrm{C} 8=$ proved to be adequate secondary substrates.

Initial bioreactor studies: validation of shake flask results Growth of recombinant $M$. ex-phaC2 and production of PHAs in shake flasks were successfully validated in a 20
L-bioreactor (14 $\mathrm{L}$ as working volume). A total of 11 $\mathrm{mL}$ of 7 -octenoic acid was added throughout the fermentation in four individual additions starting at $29 \mathrm{~h}$ of running time. After $96 \mathrm{~h}$ the final dry cell weight $(\mathrm{DCW})$ reached $5 \mathrm{~g} / \mathrm{L}$ with a $37 \%$ PHA content on a dry cell weight basis (data not shown). Polymers were extracted from biomass with chloroform and subjected to routine structural analysis. The monomeric composition reflected the results from shake flask experiments when 7-octenoic acid was fed (Tables 4 and 5). As discussed previously, PHAs produced by recombinant $M$. extorquens strains with two different PHA synthases were most likely blends of homo- and copolymers. To test for this hypothesis, extracted polymers were soaked in acetone to possibly separate SCL-PHAs from MCL3HA-containing PHAs. As opposed to MCL-PHAs, poly (3-hydroxybutyrate) (PHB) is only soluble in acetone when it is amorphous $[49,50]$. PHB separated from biomass, however, is crystalline and insoluble in acetone. As listed in Table 5, Soxhlet extraction was accompanied by a loss in PHA material. The remaining polymers were resolved into two different fractions by hot acetone. As expected, $M$. ex-phaC2 produced blends made up of SCL-PHAs and SCL/MCL-PHAs. Since the native $\mathrm{PhaC}$ enzyme is not capable of incorporating monomers other than SCL-3HA, the production of SCL/MCLPHAs must have resulted from the action of the recombinant PhaC2 enzyme. Random abundance of the different monomers is likely the reason why some MCL-3HA units remained in the acetone-insoluble fraction. It is suggested here that the MCL-3HA content was very small in some copolymeric chains so that they could not dissolve in acetone.

Our experimental PHA samples from shake flask and fermentation experiments exhibited mainly SCL-3HA monomers (3HB, C4 and $3 \mathrm{HP}=3 \mathrm{HV}, \mathrm{C} 5)$. Due to the presence of two unrelated phaC genes in our recombinant strains, we conclude that a major portion of the

Table 5 Solvent fractionation to separate SCL/MCL-PHAs from SCL-PHAs

\begin{tabular}{|c|c|c|c|c|c|c|c|}
\hline \multirow[b]{2}{*}{ PHA sample } & \multirow[b]{2}{*}{ Portion $^{2}[\%]$} & \multicolumn{6}{|c|}{ Monomeric composition of $\mathrm{PHA}^{1}$} \\
\hline & & $\begin{array}{c}\text { C4:0 } \\
{[\mathrm{mol} \%]}\end{array}$ & $\begin{array}{c}\text { C5:0 } \\
{[\mathrm{mol} \%]}\end{array}$ & $\begin{array}{c}\text { C6:5 } \\
\text { [mol\%] }\end{array}$ & $\begin{array}{c}\text { C6:0 } \\
{[\mathrm{mol} \%]}\end{array}$ & $\begin{array}{c}\text { C8:7 } \\
\text { [mol\%] }\end{array}$ & $\begin{array}{c}\mathrm{C} 8: 0 \\
{[\mathrm{~mol} \%]}\end{array}$ \\
\hline Blend $^{3}$ & - & $91.36+/-1.18$ & $0.83+/-0.02$ & $3.26+/-1.00$ & $1.31+/-0.05$ & $3.24+/-0.11$ & $\mathrm{tr}^{4}$ \\
\hline Acetone $(-)^{5}$ & 90.84 & 96.55 & 0.48 & 1.47 & 0.47 & 1.03 & - \\
\hline Acetone $(+)^{6}$ & 4.63 & $55.85+/-6.43$ & $3.33+/-0.70$ & $21.72+/-7.81$ & $6.98+/-1.56$ & $12.12+/-3.48$ & $\operatorname{tr}$ \\
\hline Loss $^{7}$ & 4.52 & - & - & - & - & - & - \\
\hline
\end{tabular}

${ }^{1} \mathrm{CX}: \mathrm{Y}=$ double bond at position $\mathrm{Y}$ of monomeric chain length $\mathrm{X}$;

${ }^{2}$ Portion after Soxhlet fractionation;

${ }^{3}$ Chloroform extract from biomass $(n=2)$;

${ }^{4} \mathrm{tr}=$ detected in trace quantity;

${ }^{5}$ Acetone-insoluble fraction ( $\left.n=1\right)$;

${ }^{6}$ Acetone-soluble fraction $(n=3)$;

${ }^{7} \mathrm{PHA}$ loss during Soxhlet extraction. 
materials consisted of $\mathrm{PHB}$ or PHBV resulting from the native PHA synthase. Since the PHA synthase coded by the phaC2 gene of $P$. fluorescens GK13 was shown to have a broad substrate specificity [23], we conclude that the remaining biopolyesters of the polymer blends belonged to the highly valuable class of short-chainlength/mediumchain-length PHAs (SCL/MCL-PHAs, $4 \leq \mathrm{C} \leq 14$ ) that have been proposed for many applications due to their desirable thermo-mechanical properties [23]. For this reason, PHBHx with a $3 \mathrm{HHx}$ content of $20 \%$ and less is currently under investigation for its potential to function as tissue engineering material ([14] and reference therein). Based on our results, we have successfully added functionality to this highly regarded class of PHAs by incorporating MCL-3HA units bearing terminal double bonds.

\section{Conclusions}

It was found that the wildtype $M$. extorquens ATCC 55366 strain could not produce functionalized PHAs starting from a methanol + unsaturated carboxylic acid mixture. As a consequence, a metabolic engineering approach was used to convert the wildtype strain into a "cell factory" capable of producing functionalized PHAs containing $\mathrm{C}-\mathrm{C}$ double bonds. The presence of the $\mathrm{C}-\mathrm{C}$ double bonds in the PHA side chains was confirmed by NMR. It was also found that the $M$. extorquens cell factory harboring the phaC2 gene appeared superior at utilizing unsaturated carboxylic acids and at incorporating $\mathrm{C}-\mathrm{C}$ double bonds into PHA starting from either $\mathrm{C} 6=$ or $\mathrm{C} 8=$. Our two $M$. extorquens cell factories were able to produce functionalized short-chain-length/mediumchain-length PHAs (SCL/MCL-PHAs), which combine desirable functionality of some MCL-PHAs with, reportedly, superior thermo-mechanical properties of inert SCL/MCL-PHAs. Double bonds may be used to induce side chain crosslinking and to covalently bind small or macromolecules upon chemical or enzymatic modifications. To date, the advantage of exhibiting functionality has been exclusively reserved for MCL- and LCL-PHAs.

\section{Appendix}

\section{Detailed analysis of NMR results}

Selected PHA samples were submitted to 1D and 2D NMR analyses to further identify which unsaturated components might be present. As example, the treatments for a PHA that was produced from methanol and 7-octenoic acid will be presented in detail. The ${ }^{1} \mathrm{H} 1 \mathrm{D}$ spectrum indicated that $3 \mathrm{HB}$ was the major component comprising over $96 \%$ of the total signal (spectrum not shown). Using natural abundance $2 \mathrm{D}^{1} \mathrm{H}^{-13} \mathrm{C}$ correlation spectra (Figure 6), it was possible to identify at least 5 minor components present which were assigned to $3 \mathrm{HP}, 3 \mathrm{HHx}, 3 \mathrm{HO}, 3 \mathrm{HHx}=$ and $3 \mathrm{HO}=$. Chemical shift assignments for these components, based on the ${ }^{1} \mathrm{H}-{ }^{13} \mathrm{C}$ Heteronuclear Single Quantum Coherence(HSQC), Heteronuclear Multiple Quantum Coherence (HMQC) and Heteronuclear 2-Bond Correlation(H2BC) 2D spectra (shown in Figure 6 as black, red and blue contour plots, respectively), are shown in Table 3 . The $2 \mathrm{D}$ spectra indicated that 5 methyl groups were present. In addition to $3 \mathrm{HB}$, the other methyl resonances were assigned to $3 \mathrm{HP}, 3 \mathrm{HHx}$ and $3 \mathrm{HO}$, and the terminal methyl. All expected single double and multiple bond correlations were observed for $3 \mathrm{HP}$ and $3 \mathrm{HHx}$. Further confirmation for $3 \mathrm{HP}$ was observed by the multiple, 3-bond correlation in the HMBC from the methyl protons (H5)to the C3 methine ${ }^{13} \mathrm{C}$ chemical shift at $71.9 \mathrm{ppm}$. Two other $\mathrm{C}$ methyl resonances at $13.8 \mathrm{ppm}$, were alleviated by their ${ }^{1} \mathrm{H}$ shifts at 0.91 and $0.88 \mathrm{ppm}$. The slightly higher frequency peak was assigned to3HHx and can be traced to the distinct $\mathrm{C} 3{ }^{13} \mathrm{C}$ chemical shift via the $\mathrm{HMBC} /$ $\mathrm{H} 2 \mathrm{BC}$ spectra (Figure 6). Based on the ${ }^{13} \mathrm{C}$ shifts for the H2BC (22.6 ppm) and HMBC (31.8 ppm) cross-peaks and comparison with previously published data [51,52], the slightly lower frequency ${ }^{1} \mathrm{H}$ methyl resonance originated from a longer chained 3-hydroxyalkanoate. We have assigned this to $3 \mathrm{HO}$ (based on the fact that we observed the related $3 \mathrm{HO}=$ polymer, see below) although we cannot exclusively rule out other longer chained monomers. Finally, at very low contour levels, we were able to detect and assign resonances at the terminus of polymer (these are too weak to detect in Figure 6 but assignments are listed in Table 3).

A notable feature of the 2D HSQC spectrum was the presence of high frequency ${ }^{1} \mathrm{H}(5.0 \mathrm{ppm}$ and $5.7 \mathrm{ppm})$ and ${ }^{13} \mathrm{C}$ (115 ppm and $\left.135 \mathrm{ppm}\right)$ resonances indicative of double bonds. These were assigned to the $3 \mathrm{HHx}=$ and $3 \mathrm{HO}=$ monomers based on the following reasoning. Firstly, the sign of these resonances in the multiplicityedited HSQC (data not shown)showed the higher frequency ${ }^{1} \mathrm{H}$ peaks $(5.7 \mathrm{ppm})$ tobe $\mathrm{CH}$ resonances $(\mathrm{C} 5$, $3 \mathrm{HHx}=$ and $\mathrm{C} 7,3 \mathrm{HO}=$ ) and the peaks at $5.0 \mathrm{ppm}$ to arise from $\mathrm{CH}$ groups ( $\mathrm{C} 6$ and $\mathrm{C} 8$ for $3 \mathrm{HHx}=$ and $3 \mathrm{HO}=$, respectively). The $\mathrm{H} 2 \mathrm{BC}$ spectrum (blue, Figure 6) showed a clear 2-bond correlation between, for example, the $\mathrm{H}$ of $\mathrm{C} 8$ and $\mathrm{C} 7$ of $3 \mathrm{HO}=($ marked $\mathrm{HO}=8,7$ on Figure 6) and the $\mathrm{H}$ of $\mathrm{C} 6$ and $\mathrm{C} 5$ of $3 \mathrm{HHx}=$ (marked $\mathrm{HH}=6,5$ on Figure 6). Thus, the double bond for both monomers must be at the end of the alkyl chain. The $3 \mathrm{HHx}=$ monomer was assigned based on the characteristic chemical shift value for C3 in 3-hydroxyalkanoatemonomers of 70.5, and the observation of a 3-bond HMBC correlation between the ${ }^{1} \mathrm{H}$ of $\mathrm{C} 5$ and a ${ }^{13} \mathrm{C}$ peak at 70.06, which must be $\mathrm{C} 3$ (labeled $\mathrm{HH}=5,3$ on Figure 6). This correlation was confirmed by the observation of the remaining expected multiple and single bond correlations for $3 \mathrm{HHx}=$ which are shown on 
Figure 6. In contrast to $3 \mathrm{HHx}=$, in $3 \mathrm{HO}=$, the $=\mathrm{CH}$ resonance $(\mathrm{C} 7$ in $3 \mathrm{HO}=)$ showed a 3 -bond $\mathrm{HMBC}$ correlation to a ${ }^{13} \mathrm{C}$ peak at $24.2 \mathrm{ppm}$ (labeled $\mathrm{HO}=7,5$ in Figure 6) which must belong to a $\mathrm{CH}$ (confirmed by the multiplicity edited HSQC experiment), indicating the alkyl chain is longer for this monomer. Assignment to $3 \mathrm{HO}=$ was once again based on the characteristic chemical shift of $\mathrm{C} 3$ andH3 at $70.5 \mathrm{ppm}$ and $5.2 \mathrm{ppm}$, respectively. Notably, the $\mathrm{C} 5$ resonance just assigned showed a 3-bond correlation to a ${ }^{1} \mathrm{H}$ resonance at 5.18 $\mathrm{ppm}$, which is probably H3. This was confirmed by the observation of the $\mathrm{H} 5$ resonance exhibiting a 3-bond correlation in the HMBC to $70.9 \mathrm{ppm}$, which must belong to $\mathrm{C} 3$. Further analysis of the HMBC and H2BC spectra confirmed this assignment, showing almost all the expected single and double bond correlations. Using the $\mathrm{C} 3$ resonances in the $\mathrm{HSQC}$ we obtained a ratio of $3 \mathrm{HB}: 3 \mathrm{HO}=(1: 0.06), 3 \mathrm{HB}: 3 \mathrm{HHx}=(1: 0.05), 3 \mathrm{HB}: 3 \mathrm{HP}$ (1:0.02), 3HB:3HHx (1:0.008, comparing10methyls), 3HB:3HO (1:0.008, comparing methyls).

\begin{abstract}
Abbreviations
3HA: 3-hydroxyalkanoate; 3HB (C4:0): 3-hydroxybutyrate; $3 \mathrm{HHx}$ (C6:0): 3hydroxyhexanoate; $3 \mathrm{HHx}=(\mathrm{C6}: 5)$ : 3-hydroxyhex-5-enonate; $3 \mathrm{HO}$ (C8:0): 3hydroxyoctanoate; $3 \mathrm{HO}=(\mathrm{C} 8: 7)$ : 3-hydroxyoct-7-enoate; $3 \mathrm{HP}(\mathrm{C} 5: 0): 3-$ hydroxypentanoate; $3 \mathrm{HV}$ (C5:0): 3-hydroxyvalerate; $\mathrm{C}$ : pentanoic acid; $\mathrm{C}=$ : 4-pentenoic acid; $t$ - $\mathrm{C} 5=$ : trans-2-pentenoic acid; $\mathrm{C} 6$ : hexanoic acid; $\mathrm{C} 6=: 5$ hexenoic acid; $C 8:=7$-octenoic acid; $C 11=:$ 10-undecenoic acid; $C X: Y$ : double bond at position $Y$ of monomeric chain length $X$; DCW: dry cell weight; GCFID: gas chromatography-flame ionization detector; H2BC: Heteronuclear 2Bond Correlation; HMBC: Heteronuclear Multiple Bond Correlation; HMQC Heteronuclear Multiple Quantum Coherence; HSQC: Heteronuclear Single Quantum Coherence; KOH: potassium hydroxide; LCL: long-chain-length; MCL: medium-chain-length; MeOH: methanol; NMR: Nuclear Magnetic Resonance spectroscopy; OD: optical density; PHB: poly(3-hydroxybutyrate); PHA: polyhydroxyalkanaote; PHBV: poly(3-hydroxbutyrate-co-3hydroxyvalerate); PHBHx: poly(3-hydroxybutyrate-co-3-hydroxyhexanoate); PPM: parts per million; SCL: short-chain-length; TMS: tetramethylsilane.
\end{abstract}

\section{Acknowledgements}

This work was partly supported by a strategic grant (No.STPGP 307509 - 04) from the Natural Sciences and Engineering Research Council of Canada (NSERC). The authors wish to thank sincerely Mrs. Chantale Beaulieu, Dr. Irena Ekiel and Mrs. Teffanie Le François, all from the NRC-BRI, for Scientific and technical assistance. Sincere thanks also to Dr. Bruce Ramsay and his group (Queen's University, Kingston, Canada) for performing several of the initial GC-FID analyses and for their precious advice at times.

\section{Author details}

'Microbial and Enzymatic Technology Group, Bioprocess Centre, Biotechnology Research Institute, National Research Council Canada, 6100 Royalmount Avenue, Montréal, Québec, H4P 2R2, Canada. ${ }^{2}$ Laboratoire de Bioingénierie et de Biophysique de l'Université de Sherbrooke, Department of Chemical and Biotechnological Engineering, Université de Sherbrooke, 2500 Boulevard de l'Université, Sherbrooke, Québec, J1K 2R1, Canada. ${ }^{3}$ Biophysics and Nuclear Magnetic Resonance, Institute for Research in Immunology and Cancer, Université de Montréal, 2900 Boulevard ÉdouardMontpetit, Montréal, Québec, H3T 1J4, Canada. ${ }^{4}$ Current Address: Oswaldo Cruz Foundation (FIOCRUZ), Bio-Manguinhos, Viral Vaccine Program, Avenida Brasil 4365, 21045-900 Rio de Janeiro/RJ, Brazil.

\section{Authors' contributions}

$\mathrm{PH}$ as PhD student carried out most of the experimental work and co-wrote the manuscript. PH also selected the two PHA synthase genes that were cloned into M. extorquens, performed the initial bioreactor studies, participated into some of the molecular biology work and analyzed all results from GC-FID. YJC and CBM used an emerging expression cassette developed by themselves and colleagues for cloning the two PHA synthase genes and for delivering a number of recombinant strains. MO performed the NMR work and was responsible for data analysis thereof. PV as PhD director and DG as co-director coordinated the study and offered general and expert supervision. All authors read and approved the final manuscript.

\section{Competing interests}

The authors declare that they have no competing interests.

Received: 3 July 2009 Accepted: 16 September 2010

Published: 16 September 2010

\section{References}

1. Bear MM, Mallarde D, Langlois $V$, Randriamahefa $S$, Bouvet $O$, Guérin P: Natural and artificial functionalized biopolyesters. II. Medium-chain length polyhydroxyoctanoates from Pseudomonas strains. J Environ Polym Degrad 1999, 7(4):179-184.

2. Keen I, Broota P, Rintoul L, Fredericks P, Trau M, Grøndahl L: Introducing amine functionalities on a poly(3-hydroxybutyrate-co-3-hydroxyvalerate) surface: comparing the use of ammonia plasma treatment and ethylenediamine aminolysis. Biomacromolecules 2006, 7(2):427-434.

3. Kenmoku T, Sugawa E, Yano T, Nomoto T, Imamura T, Suzuki T, Honma T: Polyhydroxyalkanoate that comprises unit having substituted or unsubstituted (phenylmethyl) sulfanyl structure in side chain thereof and process for producing the same. US patent 6,911,521 2005.

4. Kim DY, Kim HW, Chung MG, Rhee YH: Biosynthesis, modification, and biodegradation of bacterial medium-chain-length polyhydroxyalkanoates. J Microbiol 2007, 45(2):87-97.

5. Paik HJ, Kim YR, Orth RN, Ober CK, Coates GW, Batt CA: Endfunctionalization of poly(3-hydroxybutyrate) via genetic engineering for solid surface modification. Chem Commun 2005, 15:1956-1958.

6. Renard E, Poux A, Timbart L, Langlois V, Guérin P: Preparation of a novel artificial bacterial polyester modified with pendant hydroxyl groups. Biomacromolecules 2005, 6(2):891-896.

7. Stigers DJ, Tew GN: Poly(3-hydroxyalkanoate)s functionalized with carboxylic acid groups in the side chain. Biomacromolecules 2003, 4(2):193-195.

8. Sun Z, Ramsay J, Guay M, Ramsay B: Fermentation process development for the production of medium-chain-length poly-3-hydroxyalkanoates. Appl Microbiol Biotechnol 2007, 75(3):475-485.

9. Zinn M, Hany $\mathrm{H}$ : Tailored material properties of polyhydroxyalkanoates through biosynthesis and chemical modification. Adv Eng Mater 2005, 7(5):408-411.

10. Chen GQ, Wu Q: The application of polyhydroxyalkanoates as tissue engineering materials. Biomaterials 2005, 26(33):6565-6578.

11. Qu XH, Wu Q, Liang J, Zou B, Chen GQ: Effect of 3-hydroxyhexanoate content in poly(3-hydroxybutyrate-co-3-hydroxyhexanoate) on in vitro growth and differentiation of smooth muscle cells. Biomaterials 2006, 27(15):2944-2950.

12. Misra SK, Nazhat SN, Valappil SP, Moshrefi-Torbati M, Wood RJK, Roy I, Boccaccini AR: Fabrication and characterization of biodegradable poly(3hydroxybutyrate) composite containing bioglass. Biomacromolecules 2007, 8(7):2112-2119.

13. Philip S, Keshavarz T, Roy I: Polyhydroxyalkanoates: biodegradable polymers with a range of applications. J Chem Technol Biotechnol 2007, 82(3):233-247.

14. Hoefer P: Activation of polyhydroxyalkanoates: functionalization and modification. Front Biosci 2010, 15:93-121.

15. Park WH: Characterization of bacterial copolyesters with unsaturated pendant groups - production and thermal properties. Korea Polymer Journal 1998, 6(3):225-230.

16. Bear MM, Leboucher-Durand MA, Langlois V, Lenz RW, Goodwin S, Guérin P: Bacterial poly-3-hydroxyalkenoates with epoxy groups in the side chains. React Funct Polym 1997, 34:65-77.

17. Kim YB, Lenz RW, Fuller RC: Poly-3-hydroxyalkanoates containing unsaturated repeating units produced by Pseudomonas oleovorans. J Polym Sci Part A Polym Chem 1995, 33(8):1367-1374. 
18. Sun Z, Ramsay J, Guay M, Ramsay B: Fed-batch production of unsaturated medium-chain-length polyhydroxyalkanoates with controlled composition by Pseudomonas putida KT2440. Appl Microbiol Biotechnol 2009, 82(4):657-662.

19. Hartmann R, Hany R, Pletscher E, Ritter A, Witholt B, Zinn M: Tailor-made olefinic medium-chain-length poly[(R)-3-hydroxyalkanoates] by Pseudomonas putida GPo1: batch versus chemostat production Biotechnol Bioeng 2006, 93(4):737-746.

20. Doi $Y$, Kitamura $\mathrm{S}, \mathrm{Abe} \mathrm{H}$ : Microbial synthesis and characterization of poly (3-hydroxybutyrate-co-3-hydroxyhexanoate). Macromolecules 1995 28(14):4822-4828.

21. Chen G, Zhang G, Park S, Lee SY: Industrial scale production of poly(3hydroxybutyrate-co-3-hydroxyhexanoate). Appl Microbiol Biotechnol 2001, 57(12):50-55.

22. Green PR, Kemper J, Schechtman L, Guo L, Satkowski M, Fiedler S, Steinbüchel A, Rehm BHA: Formation of short chain length/medium chain length poly-hydroxyalkanoate copolymers by fatty acid betaoxidation inhibited Ralstonia eutropha. Biomacromolecules 2002, 3:208-213

23. Noda I, Green PR, Satkowski MM, Schechtman LA: Preparation and properties of a novel class of polyhydroxyalkanoate copolymers. Biomacromolecules 2005, 6(2):580-586.

24. Bourque D, Ouellette B, Andre G, Groleau D: Production of poly- $\beta$ hydroxybutyrate from methanol: characterization of a new isolate of Methylobacterium extorquens. Appl Microbiol Biotechnol 1992, 37:7-12.

25. Bourque D, Pomerleau Y, Groleau D: High cell density production of poly$\beta$-hydroxybutyrate $(\mathrm{PHB})$ from methanol by Methylobacterium extorquens: production of high-molecular-mass PHB. Appl Microbiol Biotechnol 1995, 44(3-4):367-376.

26. Yezza A, Halasz A, Levadoux W, Hawari J: Production of poly- $\beta$ hydroxybutyrate (PHB) by Acaligenes latus from maple sap. Appl Microbiol Biotechnol 2007, 77(2):269-274.

27. Schrader J, Schilling M, Holtmann D, Sell D, Filho MV, Marx A, Vorholt JA: Methanol-based industrial biotechnology: current status and future perspectives of methylotrophic bacteria. Trends Biotechnol 2009, 27(2):107-115.

28. Choi YJ, Morel L, Bourque D, Mullick A, Massie B, Miguez CB: Bestowing inducibility on the cloned methanol dehydrogenase promoter (PmxaF) of Methylobacterium extorquens by applying regulatory elements of Pseudomonas putida F1. Appl Environ Microbiol 2006, 72(12):7723-7729.

29. Choi YJ, Bourque D, Morel L, Groleau D, Miguez CB: Multicopy integration and expression of heterologous genes in Methylobacterium extorquens ATCC 55366. Appl Environ Microbiol 2006, 72:753-759.

30. Bradford MM: A rapid and sensitive method for the quantitation of microgram quantities of protein utilizing the principle of protein-dye binding. Anal Biochem 1976, 72(1-2):248-254.

31. Kato $M$, Bao HJ, Kang CK, Fukui T, Doi Y: Production of a novel copolyester of 3-hydroxybutyric acid and medium chain length 3hydroxyalkanaic acids by Pseudomonas sp 61-3 from sugars. Appl Microbiol Biotechnol 1996, 45(3):363-370

32. Kay $L E$, Keifer $P$, Saarinen $T$ : Pure absorption gradient enhanced heteronuclear single quantum correlation spectroscopy with improved sensitivity. J Am Chem Soc 1992, 114(26):10663-10665.

33. Bax A, Summers MF: Proton and Carbon-13 assigments from sensitivityenhanced detection of heteronuclear multiple-bond connectivity by $2 \mathrm{D}$ multiple quantum NMR. J Am Chem Soc 1986, 108(8):2093-2094.

34. Nyberg NT, Duus JO, Sørensen OW: Heteronuclear two-bond correlation: suppressing heteronuclear three-bond or higher NMR correlations while enhancing two-bond correlations even for vanishing ${ }^{2} \mathrm{~J}_{\mathrm{CH}}$. J Am Chem Soc 2005, 127(17):6154-6155.

35. Delaglio F, Grzesiek S, Vuister GW, Zhu G, Pfeifer J, Bax A: NMRPipe: a multidimensional spectral processing system based on UNIX pipes. $J$ Biomol NMR 1995, 6(3):277-293.

36. Johnson BA, Blevins RA: NMRView: a computer program for the visualization and analysis of NMR data. J Biomol NMR 1994, 4(5):603-614.

37. Chen JY, Liu T, Zheng Z, Chen JC, Chen GQ: Polyhydroxyalkanoate synthases PhaC1 and PhaC2 from Pseudomonas stutzeri 1317 had different substrate specificities. FEMS Microbiol Lett 2004, 234(2):231-237.

38. Chen JY, Song G, Chen GQ: A lower specificity PhaC2 synthase from Pseudomonas stutzeri catalyses the production of copolyesters consisting of short-chain-length and medium-chain- length 3-hydroxyalkanoates. Antonie Leeuwenhoek 2006, 89:157-167.

39. Hang X, Zhang G, Wang G, Zhao X, Chen GQ: PCR cloning of polyhydroxyalkanoate biosynthesis genes from Burkholderia caryophylli and their functional expression in recombinant Escherichia coli. FEMS Microbiol Lett 2002, 210:49-54.

40. Hein S, Paletta JRJ, Steinbüchel A: Cloning, characterization and comparison of the Pseudomonas mendocina polyhydroxyalkanoate synthases PhaC1 and PhaC2. Appl Microbiol Biotechnol 2002, 58(2):229-236.

41. Kim TK, Jung YM, Vo MT, Shioya S, Lee YH: Metabolic engineering and characterization of phaC1 and phaC2 genes from Pseudomonas putida KCTC1639 for overproduction of medium-chain-length polyhydroxyalkanoate. Biotechnol Prog 2006, 22(6):1541-1546.

42. Qi Q, Rehm BHA, Steinbüchel A: Synthesis of poly(3-hydroxyalkanoates) in Escherichia coli expressing the PHA synthase gene phaC2 from Pseudomonas aeruginos: comparison of PhaC1 and PhaC2. FEMS Microbiol Lett 1997, 157:155-162.

43. Ren Q, van Beilen JB, Sierro N, Zinn M, Kessler B, Witholt B: Expression of PHA polymerase genes of Pseudomonas putida in Escherichia coli and its effect on PHA formation. Antonie Leeuwenhoek 2005, 87(2):91-100.

44. Zhang G, Hang X, Green P, Ho KP, Chen GQ: PCR cloning of type II polyhydroxyalkanoate biosynthesis genes from two Pseudomonas strains. FEMS Microbiol Lett 2001, 198(2):165-170.

45. Liebergesell M, Fallis PL, Dong JG, Li CP, Nichols SE: Polyhydroxyalkanoate synthase genes. US Patent 6,475,734 2002.

46. Korotkova N, Lidstrom ME: Connection between poly- $\beta$-hydroxybutyrate biosynthesis and growth on C1 and C2 compounds in the methylotroph Methylobacterium extorquens AM1. J Bacteriol 2001, 183(3):1038-1046.

47. Matsusaki $H$, Abe H, Taguchi K, Fukui T, Doi Y: Biosynthesis of poly(3hydroxybutyrate-co-3-hydroxyalkanoates) by recombinant bacteria expressing the PHA synthase gene phaC1 from Pseudomonas sp. 61-3. Appl Microbiol Biotechnol 2000, 53(4):401-409.

48. Lu X, Zhang W, Jian J, Wu Q, Chen GQ: Molecular cloning and functional analysis of two poly-hydroxyalkanoate synthases from two strains of Aeromonas hydrophila spp. FEMS Microbiol Lett 2005, 243:149-155.

49. Jiang $X$, Ramsay JA, Ramsay BA: Acetone extraction of mcl-PHA from Pseudomonas putida KT2440. J Microbiol Methods 2006, 67(2):212-219.

50. Terada $\mathrm{M}$, Marchessault $\mathrm{RH}$ : Determination of solubility parameters for poly(3-hydroxyalkanoates). Int J Biol Macromol 1999, 25(13):207-215.

51. Gross RA, DeMello C, Lenz RW, Brandl H, Fuller RC: The biosynthesis and characterization of poly( $\beta$-hydroxyalkanoates) produced by Pseudomonas oleovorans. Macromolecules 1989, 22(3):1106-1115.

52. de Waard P, van der Wal H, Huijberts GNM, Eggink G: Heteronuclear NMR analysis of unsaturated fatty acids in poly(3-hydroxyalkanoates). Study of $\beta$-oxidation in Pseudomonas putida. J Biol Chem 1993, 268:315-319.

doi:10.1186/1475-2859-9-70

Cite this article as: Höfer et al:: Production of functionalized polyhydroxyalkanoates by genetically modified Methylobacterium extorquens strains. Microbial Cell Factories 2010 9:70.

\section{Submit your next manuscript to BioMed Central and take full advantage of:}

- Convenient online submission

- Thorough peer review

- No space constraints or color figure charges

- Immediate publication on acceptance

- Inclusion in PubMed, CAS, Scopus and Google Scholar

- Research which is freely available for redistribution 